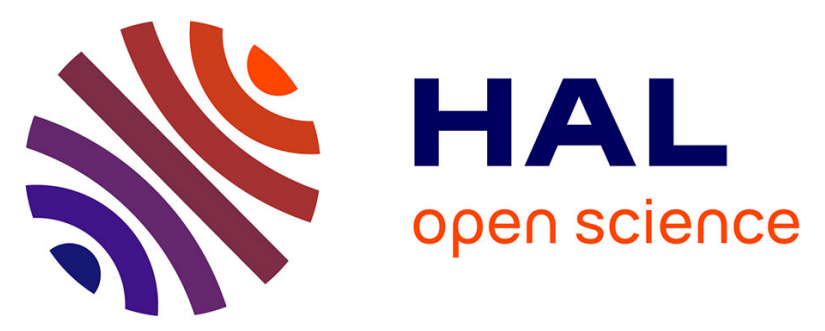

\title{
Influence of the intrinsic characteristics of mortars on their biofouling by pigmented organisms: Comparison between laboratory and field-scale experiments.
}

Thu Hien Tran, Alexandre Govin, René Guyonnet, Philippe Grosseau, Christine Lors, Denis Damidot, Olivier Devès, Bertrand Ruot

\section{To cite this version:}

Thu Hien Tran, Alexandre Govin, René Guyonnet, Philippe Grosseau, Christine Lors, et al.. Influence of the intrinsic characteristics of mortars on their biofouling by pigmented organisms: Comparison between laboratory and field-scale experiments.. International Biodeterioration and Biodegradation, 2014, 86 (Part C), pp.334-342. 10.1016/j.ibiod.2013.10.005 . hal-00908332

\section{HAL Id: hal-00908332 \\ https://hal.science/hal-00908332}

Submitted on 22 Nov 2013

HAL is a multi-disciplinary open access archive for the deposit and dissemination of scientific research documents, whether they are published or not. The documents may come from teaching and research institutions in France or abroad, or from public or private research centers.
L'archive ouverte pluridisciplinaire $\mathbf{H A L}$, est destinée au dépôt et à la diffusion de documents scientifiques de niveau recherche, publiés ou non, émanant des établissements d'enseignement et de recherche français ou étrangers, des laboratoires publics ou privés. 


\section{Influence of the intrinsic characteristics of mortars on their biofouling by pigmented} organisms: Comparison between laboratory and field-scale experiments

Thu Hien TRAN ${ }^{\mathrm{a}, \mathrm{b}, \mathrm{c}, \mathrm{e}}$, Alexandre GOVIN ${ }^{\mathrm{a}}$, René GUYONNET ${ }^{\mathrm{a}}$, Philippe GROSSEAU ${ }^{\mathrm{a}}$,

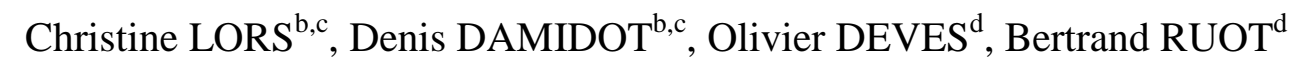

${ }^{a}$ : Ecole Nationale Supérieure des Mines de Saint Etienne, SPIN-EMSE, CNRS : UMR 5307, LGF, 158 cours Fauriel, 42023 St-Etienne, France

${ }^{\mathrm{b}}$ : Université Lille Nord de France, 1 bis Gerges Lefèvre, 59044 Lille, France

c : Ecole Nationale Supérieure des Mines de Douai, LGCgE-GCE, 941 Rue Charles Bourseul, 59508 Douai, France

d : Université Paris Est, Centre Scientifique et Technique du Bâtiment, Direction Isolation et Revêtements, 84 avenue Jean Jaurès, Champs-sur-Marne, 77447 Marne-la-Vallée, France ${ }^{\mathrm{e}}$ : Duy Tan University, Department of Civil Engineering, K7/25 Quang Trung, Da Nang, Vietnam

\section{Abstract}

Biodeterioration of mortars by the photosynthetic microorganisms is affected by their intrinsic properties such as porosity, roughness and surface $\mathrm{pH}$. The influence of these parameters was examined using an accelerated fouling test in laboratory and a natural fouling test in the real-world (in-situ). Basing on color measurement and image analysis, the impact of each intrinsic parameter was evaluated. The results differed from a scale to the other one. No influence of porosity was measured on the algal colonization rate in the laboratory test whereas, a high porosity seemed to increase slightly the bioreceptivity of the mortars exposed outdoor. The roughness, in both tests, promoted the microbial colonization. However, the discrimination of roughness grades was better in the laboratory test than in the in-situ one. 
The surface $\mathrm{pH}$ influenced remarkably on the accelerated biofouling test but not on the in-situ one. These dissimilarities resulted from the differences in experimental configurations of the two tests.

Keywords: mortar, biofouling, intrinsic properties, laboratory test, in-situ test

\section{Introduction}

The colonization of building facades by microorganisms is a subject that concerns more and more the civil engineering community. Indeed, this phenomenon changes the aesthetical appearance of materials and, in later stage, can even compromise the durability of structures by corrosion or by physical degradation induced by the microorganism (Maury-Ramirez et al., 2013). The type of microorganisms colonizing cement based building facades is diverse. But the analyses of in-situ samples show that algae are one of the initial and main colonizers (Gaylarde and Gaylarde, 2005). These microorganisms allow the successive implantation and the growth of other biological organisms such as lichens and bryophytes. If no solution is found, the pteridophytes and higher plants may also appear (Perrichet, 1984; Deruelle, 1991; Barberousse, 2006). The microbial development must be eliminated to avoid worse consequences to buildings. The more the cleaning maintenance activities are repeated the more expensive the cost.

Several factors such as the global climate, the local environment, the building design and the facade materials influence the biological fouling.

The rainfall, the wind and the temperature consist in the climatic parameters influencing together the water availability of facade materials which is an essential element to the microbial metabolism. A permanently wet facade promotes the growth of algae and higher 
plants (Ariño and Saiz-Jimenez, 1996; Loh, 2002). Therefore, the facades represent a higher susceptibility to biofouling in the rainy regions and during the heavy rainy season (Young 1997). However, a high temperature induces water evaporation by heating the materials. Similarly, the wind can cause a drying phenomenon.

The local environmental conditions, such as topography and nature of the ground, presence of moisture and/or industrial activities around the buildings, should be taken into account. As an example, a house roof, located close to seaside, can be totally colonized by nitrophilous lichens, characterized by the yellow or orange, in a few years (Deruelle, 1991). Indeed, sea sprays, by providing nitrogen to the building surface, favor the microorganism growth. In addition, the humid environments set near a lake, a river, trees or shrubs, are favorable to the appearance of stains on the walls.

The growth of biological fouling is also depending on the orientation of the facade. Indeed, the north-facing facades which are wetter and less sunny, get colonize faster (Ariño and Saiz-Jimenez, 1996; Young, 1997; Barberousse, 2006). Similarly, a facade exposed to dominant winds seems to be colonized more easily than the other sides of the same building. The wind can transport both the rain and the biological propagules at the facades promoting the biofouling.

Parts of building often moistened for long periods, or easily covered of propagules, are highly sensitive to the biological colonization (Wee and Lee, 1980). The biofouling often grows at the foot of walls, the junction of different coatings and the overhanging elements (cornices, moldings, balconies, etc.) (Wee and Lee, 1980; CSTB, 2005; Barberousse, 2006).

In addition to external conditions, the biological development is affected by the intrinsic characteristics of the facade, defined as its bioreceptivity (Guillitte, 1995). These 
characteristics can be divided into physical properties (porosity, roughness and hydrodynamic properties) and chemical ones (chemical composition, $\mathrm{pH}$ surface).

Since the last thirty years, several researches have been devoted to the study of the building-materials bioreceptivity. In all these studies, the experimental tests were conducted with more or less accelerated methods of the biological growth on materials. The goal of these accelerated methods was to reduce the test duration, which normally required many years in the real-world. The experimental parameters were thus optimized to favor the growth of microorganisms (Dubosc et al., 2001; Barberousse, 2006). Different methodologies, concerning the preparation of materials, the process of inoculation and humidification, the temperature and the photoperiod of the test were developed (Grant and Bravery, 1985; Guillitte and Dreesen, 1995; Ohshima et al., 1999; Dubosc et al., 2001; Miller et al., 2006; Miller et al., 2009; De Muynck et al., 2009; Tran et al., 2012). According to all these studies, the roughness of materials appears as one of the most important parameters. Indeed, the colonization of the building materials by microorganisms is promoted by the roughness of the surface. In fact the roughness provides many asperities and thus increases the physical anchorage of these micro-organisms (Dubosc, 2000; Tran et al., 2012). This effect of roughness on the biofouling was confirmed by observations of buildings in real conditions (Wee and Lee, 1980; Darlington, 1981; Pietrini et al., 1985; Joshi and Mukundan, 1997). The total porosity, the pore size distribution and the porous network, should be taken into account, because the absorption and the water retention of materials are controlled by these characteristics (Warscheid et al., 1993; Ohshima et al., 1999; Crispim et al., 2003; Miller et al., 2006; Miller et al., 2009). Furthermore, the inhibition of the algal growth by high pH of material surface is commonly mentioned (Grant, 1982).

Most of previous studies propose only a qualitative evaluation of the biofouling or a comparison of very different materials. In order to accelerate the fouling, mortars are usually 
aged (by carbonation and/or leaching) to decrease the surface alkalinity. But the effect of the accelerated aging is rarely evaluated. Moreover, the experimental conditions of accelerated tests are significantly far from the real conditions. The investigations in field-scale are rarely conducted because of the long duration of the experiments (Young, 1997; Ohshima et al., 1999; Lengsfeld and Krus, 2004). Thus, the relationship between bench-scale experimental results and field-scale experimental results is scant.

This work aims to clarify the effect of porosity, roughness and carbonation, on the building-materials colonization by algae at laboratory and in-situ scale. One unique mortar formulation has been investigated. The kinetic of the biological colonization was studied.

\section{Materials and methods}

\subsection{Preparation and characterization of samples}

Portland cement (CEM I 52.5, Holcim), siliceous sand (Sibelco DU 0.1/0.35), calcareous filler (Omya) and cellulose ether (Hydroxylethyl Methyl Cellulose, SE-Tylose) were mixed according to the proportions summarized in Table 1 to prepare the studied samples. The water-to-cement ratio $(w / c)(\mathrm{wt} / \mathrm{wt})$ was fixed at 1 and 1.2. These two $w / c$ were considered in order to modify the porosity without changing the chemical composition of mortars.

Table 1

Mortar formulation

\begin{tabular}{ccccc}
\hline Component & Cement & Sand & Calcareous Filler & Admixture $^{\mathrm{a}}$ \\
\hline$\%$ mass of dry mixture & 30 & 65 & 5 & 0.27 \\
\hline
\end{tabular}

\footnotetext{
${ }^{a}$ in addition to dry mixture (cement, sand and filler)
} 
The variation of sample surface $\mathrm{pH}$ was achieved by a curing process. Mortars were subjected (called carbonated mortars) or not (called uncarbonated mortars) to ageing by accelerated carbonation prior to the start of biofouling test.

After mixing, the fresh mortar was casted into $50 \mathrm{~cm} \times 50 \mathrm{~cm} \times 1 \mathrm{~cm}$ extruded polystyrene molds. The fresh mortar was stored at $21 \pm 1{ }^{\circ} \mathrm{C}$ and $95 \pm 5 \%$ of relative humidity during 28 days for the uncarbonated samples. The mortar plates were then cut into samples of $20 \mathrm{~cm} \times 8$ $\mathrm{cm} \times 1 \mathrm{~cm}$ and of $20 \mathrm{~cm} \times 30 \mathrm{~cm} \times 1 \mathrm{~cm}$ for the laboratory tests and the in-situ tests, respectively. For the carbonated samples, the fresh mortar was stored in the aforementioned conditions for only 7 days before being cut. This premature curing end aimed to shorten the total duration of specimen production and to obtain the closest total storage time as possible between carbonated and uncarbonated samples.

The samples were then exposed to pure $\mathrm{CO}_{2}$ at $21 \pm 1{ }^{\circ} \mathrm{C}$ and $65 \pm 5 \%$ of relative humidity until the complete carbonation. This carbonation process required 36 days. The $\mathrm{pH}$ was verified by spraying a phenolphthalein solution $(0.2 \%$ in ethanol) on the entire thickness of specimen. The discoloration of the solution indicated a diminution of $\mathrm{pH}$ to about 9 (Thiery, 2005).

Moreover, the surface $\mathrm{pH}$ of mortar was measured by means of a surface electrode (WTW Sentix Sur). For each sample, six measurements were performed at six positions distributed over the sample surface. A constant volume of distilled water $(0.1 \mathrm{ml})$ was deposed on the related position. The electrode was kept in contact with the sample surface during a fixed time of 30 seconds. The $\mathrm{pH}$ value was then recorded and the surface $\mathrm{pH}$ of sample was the average of these six values. The surface $\mathrm{pH}$ of sample was monitored twice a week during the carbonation process. 
The pore size distribution and the total porosity of materials were determined using mercury intrusion porosimetry (Micromeritics Autopore IV 9400). Three samples were measured for each mortar formulation, i.e. $w / c$ ratio of 1 and 1.2, both uncarbonated after 28 days of curing and carbonated after 7 days of curing and 36 days of accelerated carbonation. They were beforehand dried by acetone to evacuate the open pores.

To obtain several surface roughnesses, three surface finishing methods were applied during the sample setting. The first one consisted in smoothing the surface of fresh mortars with a ruler and the two others in scratching the surface of the setting mortars with sponges of two different roughnesses.

The roughness of the mortar specimens was evaluated by means of an optical profilometer (CHR-150-L). The arithmetic average of the height $R_{a}$ was determined from the measurements of the surface profile (Gadelmawla et al., 2002). Measurements consisted in analyze 161 profiles of $7 \mathrm{~cm}$ length and spaced of $500 \mu \mathrm{m}$. The data was recorded each $20 \mu \mathrm{m}$ along each profile. The value Ra, representative of the sample roughness, corresponded to the average of 563.661 measuring points.

Each mortar was labeled by four codes. The first one corresponds to the $w / c$ ratio, the second to the carbonation state, the third to the roughness and the last to the scale of the biofouling test. For example, a sample labeled 1UC-R1-Lab corresponded to the uncarbonated mortar prepared with a $w / c$ ratio of 1 with the smoothest roughness and tested in the laboratory experiment.

The laboratory experiments consisted in an accelerated algal growth on cementitious materials. A closed device containing an algal suspension was set up. The microalgae 
ease of liquid culture. The suspension was periodically sprinkled on the samples surface. The run-off period was fixed to 90 min every $12 \mathrm{~h}$. The light was provided by two neon lamps during $12 \mathrm{~h}$ per day, and was set to start simultaneously with the run-off cycles. All the experimental configurations (rate of sprinkling, light intensity, temperature, initial concentration of the algal suspension and angle inclination of the samples) were kept constant. The details of the experimental approach were described in previous papers (Tran et al., 2012; Tran et al., 2013).

In laboratory experiments, specimens with dimension of $20 \mathrm{~cm} \times 8 \mathrm{~cm} \times 1 \mathrm{~cm}$ were tested in triplicate for each material. Carbonated and uncarbonated samples were tested separately. Therefore, 18 samples were introduced in the test-chamber for each experiment.

The field-scale experiments consisted in a natural development of microorganisms on cementitious materials. The mortar samples were placed on a stainless steel frame in a private green park close to Grenoble, France. The sample dimensions were larger than the ones used in the laboratory test, i.e. $20 \mathrm{~cm} \times 30 \mathrm{~cm} \times 1 \mathrm{~cm}$. The larger dimensions aimed to minimize all the non-representative effect resulted from the natural incidental events such as a random intense inoculation of microorganisms at an individual sample points, the deposition of bird droppings on the sample surface, etc.

The exposure of materials to the outdoor conditions started on 26 June 2009 and lasted one year and a half. The experimental configurations were chosen in order to favor the biological colonization of the sample surface. The samples were placed near trees, facing the north direction and inclined with an angle of $45^{\circ}$. The specimens were arranged in two rows of which the first was located at $1 \mathrm{~m}$ above the ground to avoid splashing during rainy periods. The contamination between specimens by water flow was also avoided (Fig. 1). 


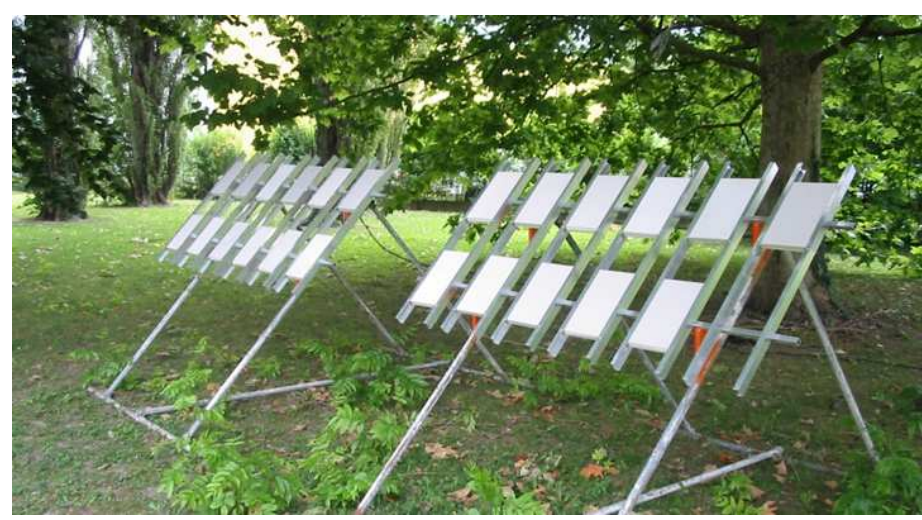

Fig. 1. Experimental set-up for the in-situ tests.

Each material was tested in triplicates. The mortars with a $w / c$ ratio of 1 were studied at carbonated and uncarbonated states, with the three roughnesses. For the samples with a $w / c$ ratio equal to 1.2 , only the carbonated mortars with the two highest roughnesses were examined.

\subsection{Evaluation criteria of biofouling}

The biological colonization of mortar surface was evaluated by means of image analysis and colorimetric measurements.

Concerning the image analysis, the surface of samples was digitized using Epson V300 office scanner. The images obtained in the RGB color space were converted into the YIQ color space. The distinction between the areas covered by algae and the surfaces of clean mortars were achieved on the $\mathrm{Q}$ channel (Tran et al., 2012). The colonization rate $(X(t)(\%))$ was then given by the ratio of the fouled areas to the total surface of the sample. The samples from the lab-scale and field-scale experiments were scanned every weekday and at least every two months, respectively.

The colorimetric measurements were performed using colorimeters (Minolta CM-2600d for the laboratory tests and Konica Minolta Chroma CR-410 for the in-situ tests). For each 
specimen, the measurements were conducted at fixed positions spread over the whole sample surface. Thirty six and eighteen measurements were monitored on a lab sample and an in-situ one, respectively. The sample area of each measurement was of $0.5 \mathrm{~cm}^{2}$ and $19.6 \mathrm{~cm}^{2}$, respectively. The CIE Lab color space data ( $L^{*}, a^{*}, b^{*}$ coordinates) were collected. The data was monitored three times a week on the lab specimens and at least every two months for the field-scale specimens. In order to evaluate the color changes of the test specimens, for each color coordinate $\left(L^{*}, a^{*}, b^{*}\right)$, the difference between sample at a given time and the same sample at the initial time (uncolonized sample) was determined $\left(\Delta L^{*}, \Delta a^{*}, \Delta b^{*}\right)$.

\section{Results}

\subsection{Characterization of materials}

The porosity, the surface $\mathrm{pH}$ and the roughness of each mortar are given in Table 2 . For the samples made with $w / c$ ratio equal to 1 (i.e. uncarbonated and carbonated), the values of the porosity, the surface $\mathrm{pH}$ and the roughness $\mathrm{R} 1$ were those of a previous paper (Tran et al., 2012).

\section{Table 2}

Characteristics of mortars

\begin{tabular}{|c|c|c|c|c|c|c|}
\hline & $\begin{array}{l}\text { Ratio } \\
w / c\end{array}$ & $\begin{array}{l}\text { Porosity } \\
(\%)\end{array}$ & $\begin{array}{l}\text { Surface } \\
\mathrm{pH}\end{array}$ & & Code & $\mathrm{R}_{\mathrm{a}}(\mu m)$ \\
\hline \multirow[t]{6}{*}{ Uncarbonated } & 1 & $37.2 \pm 0$ & $11 \pm 0.4$ & Roughness 1 & 1UC-R1 & $29 \pm 5$ \\
\hline & & & & Roughness 2 & 1UC-R2 & $47 \pm 6$ \\
\hline & & & & Roughness 3 & 1UC-R3 & $70 \pm 8$ \\
\hline & 1.2 & $38.9 \pm 0.3$ & $11.0 \pm 0.3$ & Roughness 1 & 1.2UC-R1 & $29 \pm 5$ \\
\hline & & & & Roughness 2 & 1.2UC-R2 & $47 \pm 6$ \\
\hline & & & & Roughness 3 & 1.2UC-R3 & $123 \pm 9$ \\
\hline \multirow[t]{6}{*}{ Carbonated } & 1 & $32.1 \pm 1.9$ & $9.0 \pm 0.1$ & Roughness 1 & 1C-R1 & $29 \pm 5$ \\
\hline & & & & Roughness 2 & $1 \mathrm{C}-\mathrm{R} 2$ & $47 \pm 6$ \\
\hline & & & & Roughness 3 & 1C-R3 & $138 \pm 15$ \\
\hline & 1.2 & $36.2 \pm 0.1$ & $8.9 \pm 0.1$ & Roughness 1 & $1.2 \mathrm{C}-\mathrm{R} 1$ & $32 \pm 4$ \\
\hline & & & & Roughness 2 & $1.2 \mathrm{C}-\mathrm{R} 2$ & $47 \pm 6$ \\
\hline & & & & Roughness 3 & $1.2 \mathrm{C}-\mathrm{R} 3$ & $145 \pm 18$ \\
\hline
\end{tabular}


The total porosity of uncarbonated mortars varied from 37 to $39 \%$, which is coherent with the literature (Monge 2007). The mortars with the highest $w / c$ ratio were slightly more porous. According to Lafhaj et al. (2006), the porosity increases non-linearly with the $w / c$ ratio. When this $w / c$ ratio is high, its effect on the total porosity is attenuated.

The carbonated mortars were less porous than the uncarbonated ones, i.e. $32 \%$ for $1 \mathrm{C}$ against $37 \%$ for $1 \mathrm{UC}$ and $36 \%$ for $1.2 \mathrm{C}$ against $39 \%$ for $1.2 \mathrm{UC}$. It is known that the carbonation leads to a reduction of pore volume. Houst (1992) noted that this reduction of the total porosity is even more enhanced by a low $w / c$ ratio.

Depending on the curing process, two levels of surface $\mathrm{pH}$ were obtained. The surface $\mathrm{pH}$ reached 11 with the standard curing (uncarbonated samples) and 9 by accelerated carbonation. Moreover, no effect of the $w / c$ ratio on the surface $\mathrm{pH}$ was detected. Indeed, the same value of surface $\mathrm{pH}$ was measured for both $w / c$ ratios.

Three levels of roughness were obtained whatever the curing process and the $w / c$ ratio. The smoothest surface (R1), without reliefs, was achieved by the method of finishing to the rule. The rougher surfaces were obtained by scratching the sample surfaces with sponges. Both strong reliefs and asperities appeared on the roughest surface (R3). Moreover, a remarkable discrimination between the highest roughness (R3) and the intermediate one (R2) was observed. In fact, the $R_{a}$ values were 2.5 to 5 times higher for $\mathrm{R} 3$ than for $\mathrm{R} 2$. As a comparison, the difference between the $\mathrm{R} 2$ and $\mathrm{R} 1$ was only about 1.5 times.

\subsection{Biological colonization of cementitious materials in laboratory and field test}

Fig. 2 illustrates the biological fouling of specimens investigated in the accelerated tests and the in-situ experiments over time. 


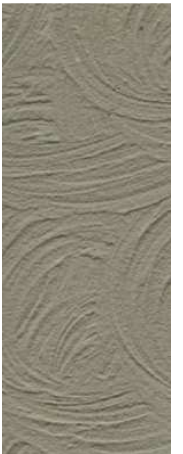

1 day

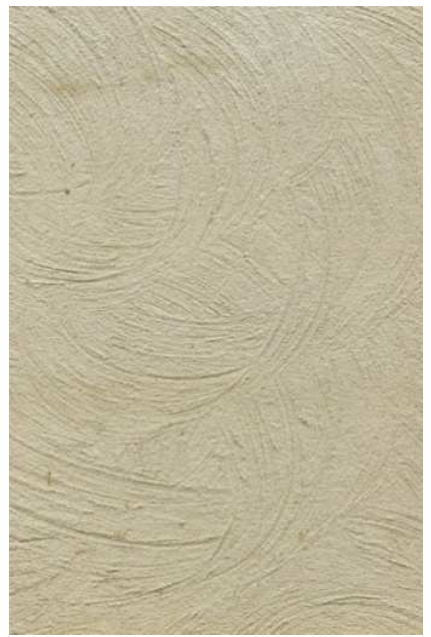

25/06/2009

0 month

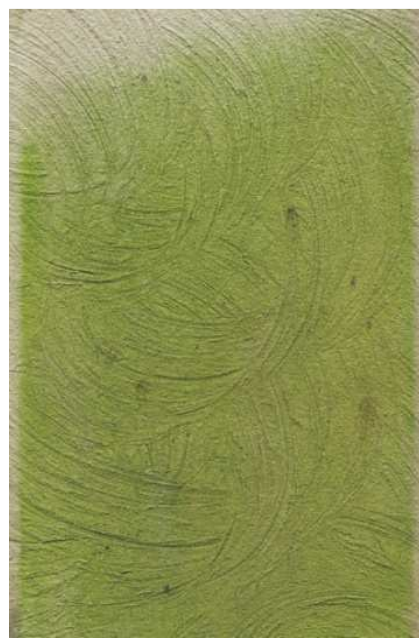

20/10/2010

16 months

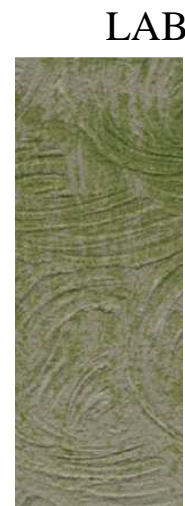

11 days

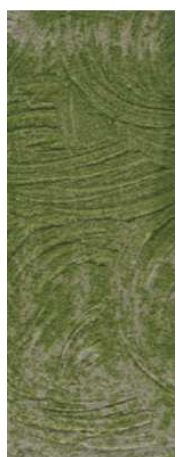

19 days

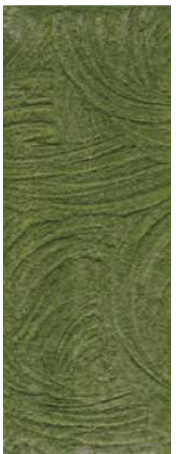

25 days

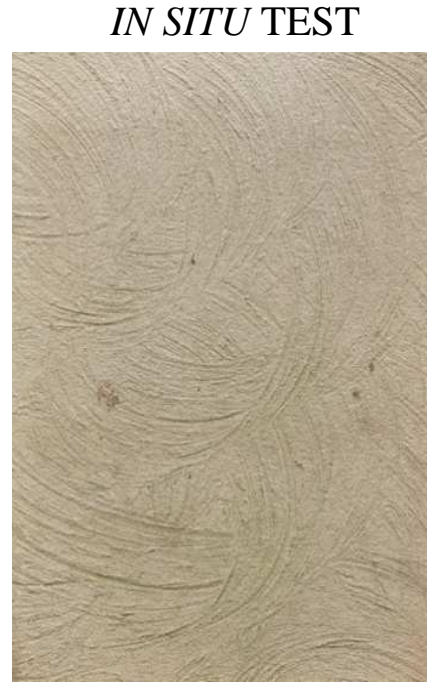

19/07/2010

13 months

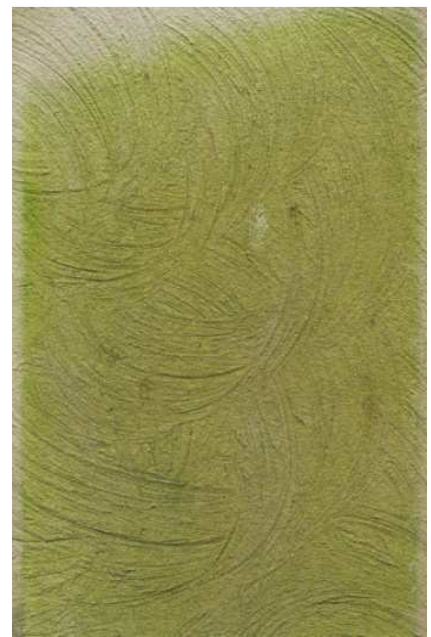

$24 / 11 / 2010$

17 months

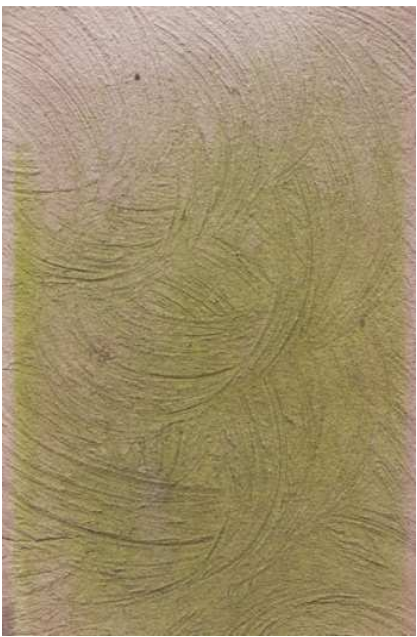

$14 / 09 / 2010$

15 months

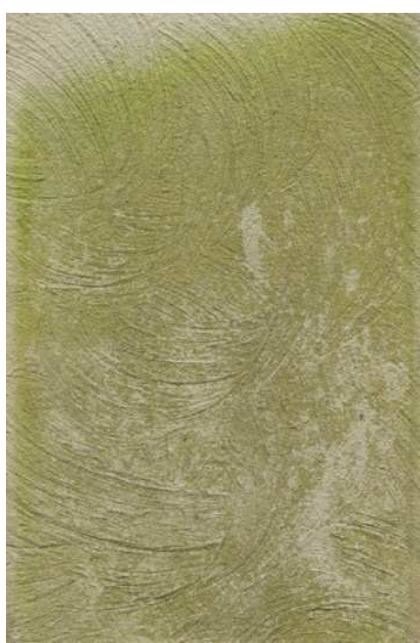

$06 / 1 / 2011$

18.5 months

Fig. 2. Surface colonized by algae over time for carbonated mortars, $w / c$ of 1.2 and roughness R3. 
In the laboratory tests, the colonization of the surface by Klebsormidium flaccidum created a dense and velvety mat as previously shown by Tran et al. (2012; 2013). The first algal spots appeared at privileged sites of the surface, such as air bubble holes or asperities formed by the roughness. The extension of fouling resulted from the growth of the existent spots and the adhesion of new ones. On the sample surface of lowest roughnesses (R1 and R2), the algal development formed streaks due to the suspension flow. This fouling form was usually observed on the building facades. On the roughest mortars (R3), the fouling followed the asperities on the surface which conducted the flows of the algal suspension.

The sample exposure in the natural conditions began at summer (end of June 2009). The 255 first settlement appeared on the mortars 1.2C-R3, after 11.6 months of exposure. The the latency period, the biological colonization developed rapidly. Four and a half months later, the fouling was observed on the whole in-situ specimens.

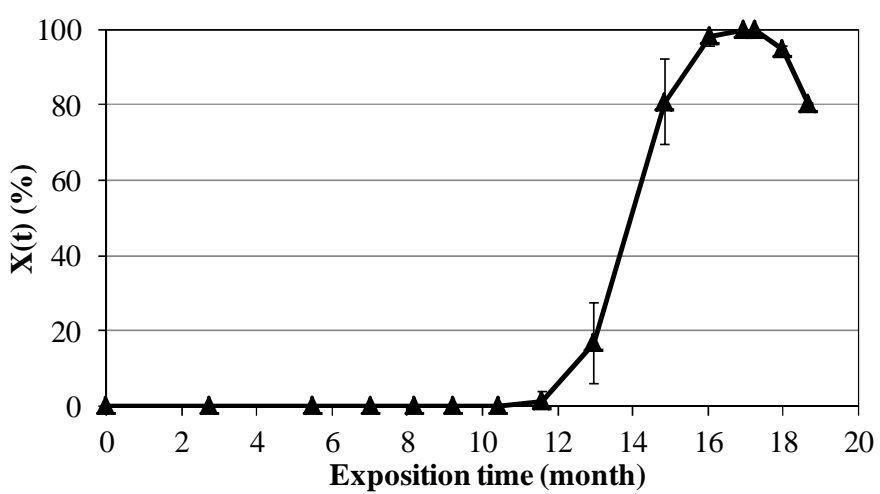

The same latency time was observed by Dubosc (2000) and Young (1997) for carbonated mortars and sandstone samples, respectively. The biological development accelerated during the autumn period (August to November, i.e. 13 to 17 months of exposure). The same 
observation was made by Warscheid et al. (1993) on stone samples exposed to outdoor conditions in different locations in Germany.

The propagules of microorganisms might be already settled on the mortar surface since the spring. Fig. 4 shows the monthly average values of rainfall and air temperature during the experimental time. In spring 2010 (April and May corresponding to 10 and 11 months respectively), the meteorological data highlighted high precipitation and medium temperature (i.e. about $15{ }^{\circ} \mathrm{C}$ ). The following summer corresponded to the harsher climate, especially in July (12-13 months), with the highest average temperatures and the lowest precipitations of the year. During this period, the water available for the microorganism development was very limited. Then mild temperatures accompanied with a suitable rainfall in autumn (September and October corresponding to 15 and 16 months of exposure respectively) favored remarkably the algal growth. From December (18 months), the detachment of algae from the samples surface was observed. It corresponds to the winter period characterized by very low temperatures, weak density of lighting and snow. The aging of microorganisms in this season might be the reason of theirs detachment.

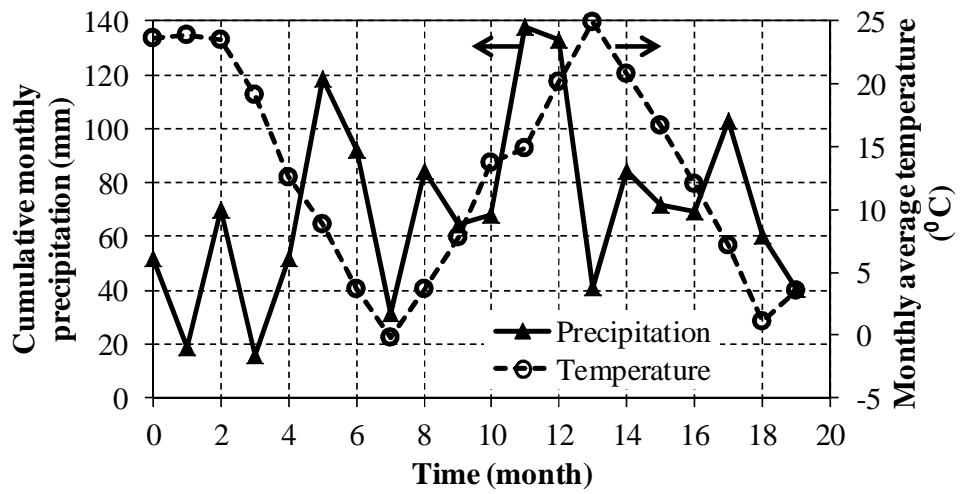

Fig. 4. Monthly average air temperature and cumulative precipitation during the in-situ test.

Fig. 5 represents the color changes of carbonated mortars of roughness R3, tested in laboratory and field-scale. All the graphs show the mean values and the standard deviation of 
three specimens. The evolution of clarity $\Delta L^{*}$ and chromaticities $\Delta a^{*}, \Delta b^{*}$ showed the same trends for the two test scales. The $\Delta L^{*}, \Delta a^{*}$ decreased while the $\Delta b^{*}$ increased with time. The samples could be attributed to these microorganisms.
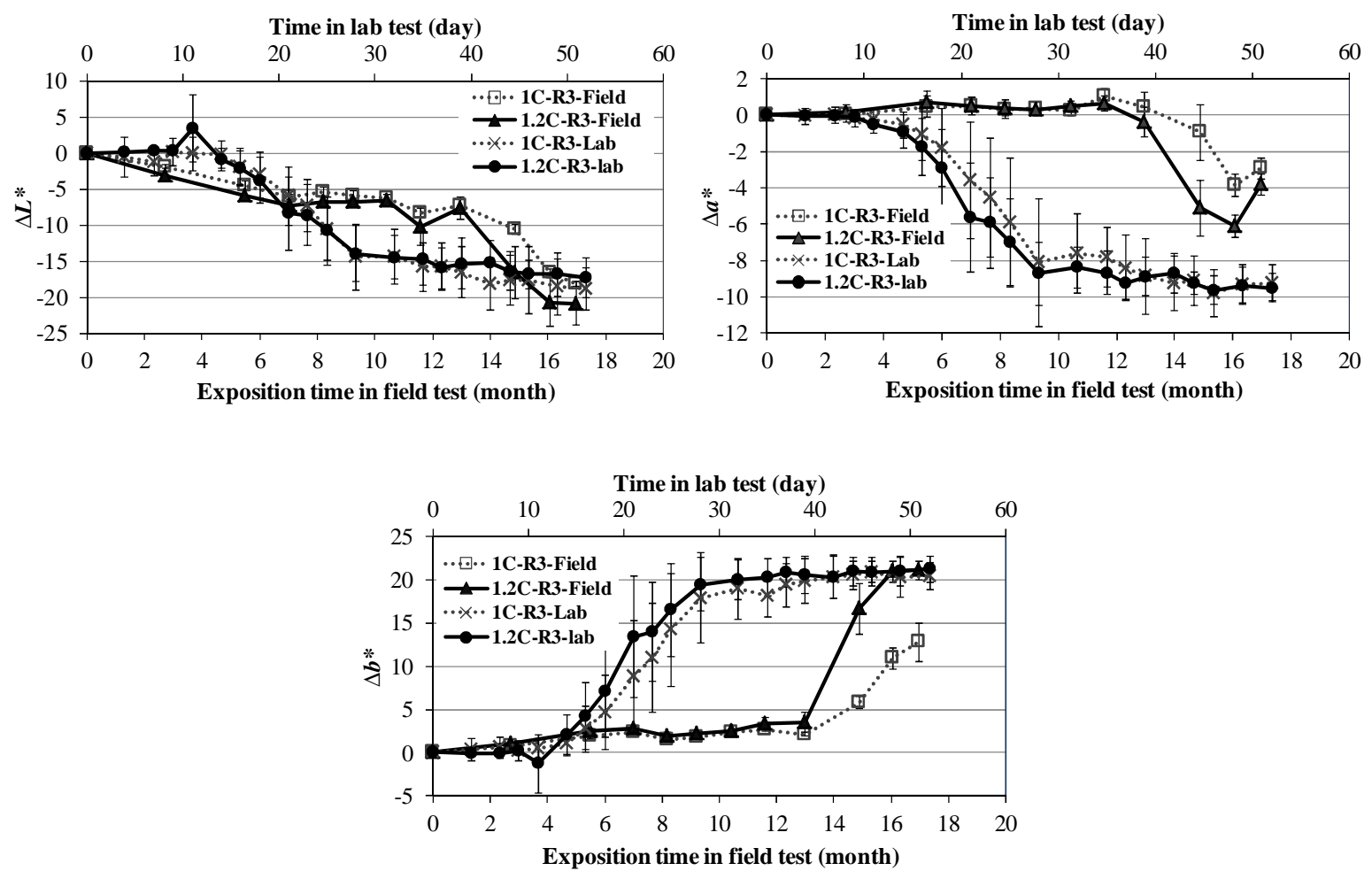

Fig. 5. Evolution of the clarity $\Delta L^{*}$ and the chromaticities $\Delta a^{*}, \Delta b^{*}$ of mortars with the

\subsubsection{Effect of $w / c$ ratio}

Fig. 6 shows the influence of the $w / c$ ratio ( 1 and 1.2) on the biofouling rate of carbonated mortars (three roughnesses). 

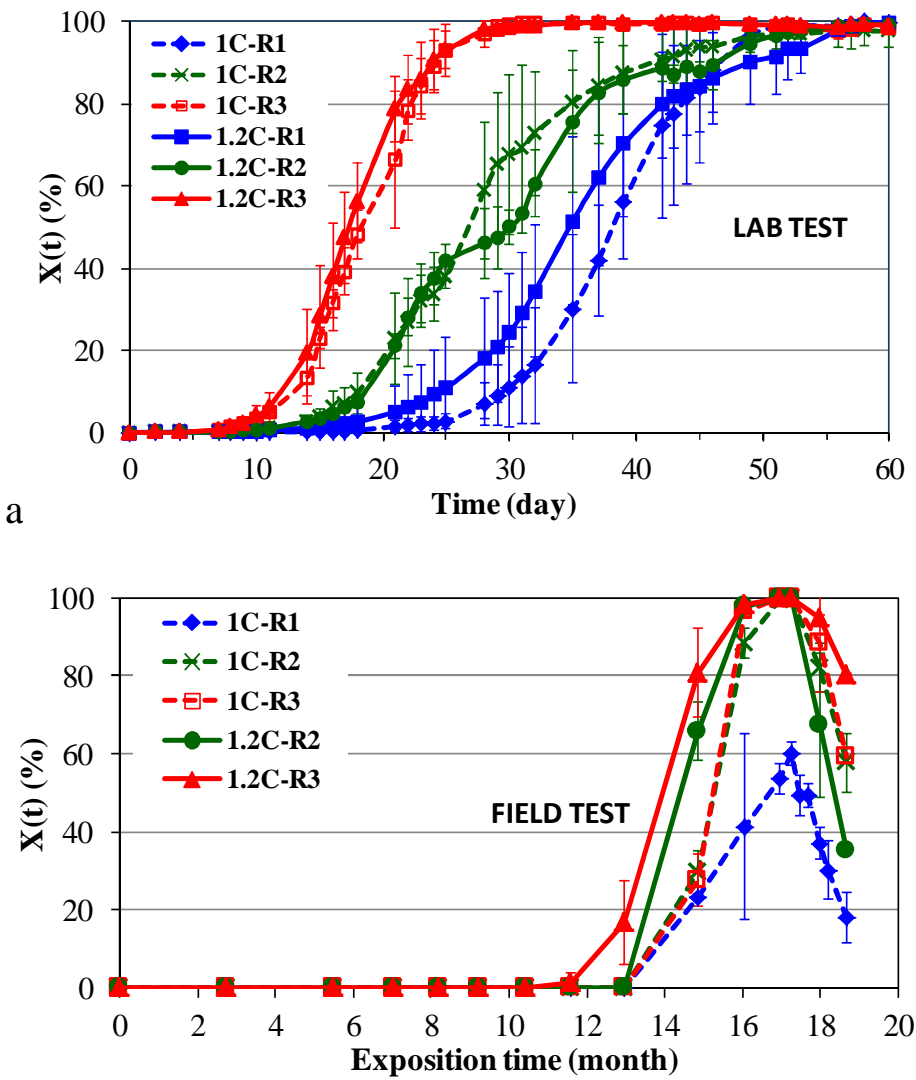

301

b

Fig. 6 Effect of $w / c$ ratio and roughness on the colonization rate for carbonated mortars in laboratory (a) and field test (b).

In the lab test, the algal colonization curve was of sigmoid type. Three steps can be identified: a latency step, an exponential growth step and a step of stagnation. For each roughness (R1, R2 and R3), no effect of the $w / c$ ratio was identified on algal coverage. In fact, for the roughest mortars (R3), the fouling rate evolved quite identically. The algal colonization appeared after 6 testing days and the entire surface was covered after 30 days. For the two other roughnesses, with such experimental standard deviation, the colonization rate of the less porous mortars (1C) could be considered similar to the one of the more porous mortars (1.2C).

Unlike in the accelerated test, in the real conditions, an effect of the $w / c$ ratio was detected. Indeed, the mortars made with a $w / c$ ratio of 1.2 presented a faster microbial development 
than the ones prepared with a $w / c$ ratio of 1 . For the $1.2 \mathrm{C}-\mathrm{R} 3$ samples, the biofouling appeared between 11 and 13 months of exposure. At the same moment, no algal colonization was observed on the mortar $1 \mathrm{C}$. The following measures, realized two months later, showed a coverage area of $80 \%$ for $1.2 \mathrm{C}$ mortars against only $30 \%$ for $1 \mathrm{C}$ mortars. For the intermediate roughness (R2), the effect of $w / c$ ratio was less important. $30 \%$ of the mortars $1 \mathrm{C}$ was colonized while it was 2 times higher on the mortar $1.2 \mathrm{C}$. One month later, only the more porous mortar was totally colonized.

The color changes of the roughest mortar confirmed the results obtained from the images analyses (Fig. 5). Indeed, the color intensity of 1.2C-R3-Field mortars evolved faster than the one of 1C-R3-Field mortars. Furthermore, the change in color intensity between these two mortars occurred after 13 months of exposure. Concerning the bench-scale experiments, the evolution of the color and the colonization rate coincided perfectly regardless of the $w / c$ ratio. Indeed, an increase in the color intensity was detected between 4 and 28 days of exposure. Then, no color evolution was observed since the 28th days of testing, corresponding to the necessary time for a complete biofouling.

\subsubsection{Effect of the roughness}

For the bench-scale test, the biofouling rate was obviously influenced by the surface roughness of samples (Fig. 6a). The effect of the three levels of roughness tested on the biofouling were quite distinct, whatever the $w / c$ ratio (1 and 1.2). The smoothest roughness (R1) exhibited the lowest colonization rate and the highest latency time. Indeed, the latency time was around 18 days of testing for roughness R1, against 9 and 6 days for roughness R2 and R3, respectively. Similarly, the complete colonization was achieved more quickly on the rougher mortars, i.e. in 30 days for R3, against 51 and 56 days for R2 and R1, respectively. Furthermore, the curve slope evolved in the same way as the roughness during the 
exponential growth phase. The more the roughness was high, the more the colonization was quick.

The roughness impacted also the biological development of mortars exposed in the realworld (Fig. 6b). However, unlike bench-scale test, only two grades of roughness (i.e. rough and smooth) were observed. The mortars of very different roughness, R2 and R3, showed no difference in bioreceptivity to visible photosynthetic organisms. This result was particularly obvious for $w / c=1$. Conversely, a transition from a smooth surface (R1) to a rough one (R2) remarkably increased the bioreceptivity of mortars. Indeed, the colonization appeared slower for the mortar R1 than for the two others. The entire surface of samples R2 and R3 was colonized after 17 months (November 2010). For the same duration, only $60 \%$ of mortar surface R1 was colonized. Beyond this time, a decrease in the covered area was noticed for all samples. It has been assigned to detachment of algae. The detachment rate was similar for all mortars of $w / c$ equal to 1 . However, for mortar of $w / c$ equal to 1.2 , smooth surface showed a faster decrease in the coverage area compared to the rough one. Hence, the effect of roughness on the microbial detachment rate remains difficult to analyze.

\subsubsection{Effect of the accelerated carbonation}

Fig. 7 illustrated the evolution of the colonization rate for carbonated and uncarbonated mortars mixed with a $w / c$ ratio of 1 , for the lowest and the highest roughness.

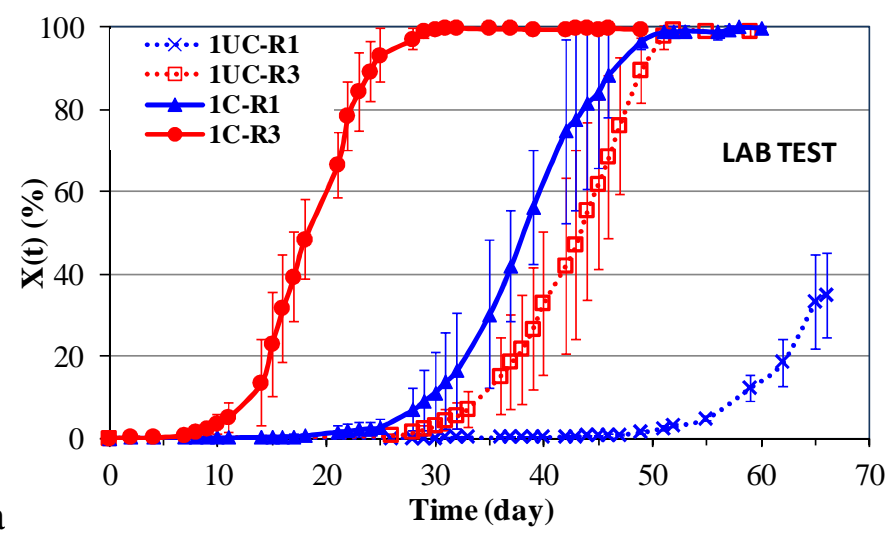




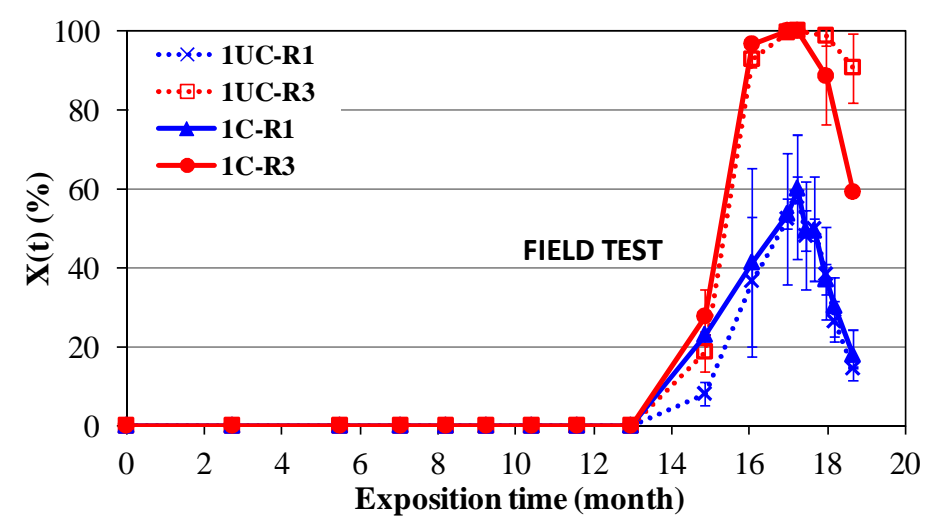

b

Fig. 7. Effect of accelerated carbonation on the colonization rate for mortars mixed with a $w / c$ ratio of 1 , with roughness $\mathrm{R} 1$ and $\mathrm{R} 3$, in laboratory (a) and field test (b).

The carbonation seemed to be the most decisive parameter on the bioreceptivity of materials for the accelerated fouling test. It significantly shortened the latency time, and accelerated the rate of algal colonization. As showed in the Fig. 7, the latency time of 1C-R1 mortar was of 18 days. This value was 2.6 times less than that of 1UC-R1 mortar (46 days). Similarly, the colonization of 1C-R3 mortar began after 7 days against 26 days for 1UC-R3 mortar. The complete colonization was reached in 30 days for the 1C-R3 mortar against 51 days for the 1UC-R3 one. It is worth noting that, the total colonization of 1UC-R1 was not obtained because of a precocious stop of testing. Nevertheless, basing on the roughest mortars, the slope of the curve was greater for carbonated mortars than for uncarbonated ones.

In the field-scale test, it seems that the accelerated carbonation did not result in different growth profiles. The biofouling evolved quite identically on carbonated and uncarbonated mortars. For both mortars $1 \mathrm{UC}$ and $1 \mathrm{C}$, and of roughness R1 or R3, the colonization by microorganisms began at the same moment, i.e. after 13 months. Then, 4 months later (November, corresponding to 17 months of exposure), the entire surface of all rough samples (R3) was colonized. At this same time, the algal colonization reached a common rate of around $60 \%$ for smoothest samples (R1), carbonated or uncarbonated. From 18 months 
378 (December 2010), a decrease of fouled area was observed on the entire surface due to the

379 microbial detachment. It seems that the detachment rate was not dependent on the initial 380 carbonation state of mortars.

\section{Discussion}

The results obtained from the color measurements and the image analysis, are coherent and complementary. Indeed, the effect of intrinsic characteristics of mortars on their bioreceptivity was found identical by these two methods. Due to monitoring the entire surface of samples, the color changes are well representative of the fouled area.

The color evolution of the surface of the samples, for both laboratory and in-situ tests, was quite identical, i.e. more and more dark, green and yellow. The fouling of the in situ samples is thus presumably associated to green algae. These microbial species are the primary and main colonizers on building facades as noticed by several authors (Wee and Lee, 1980; Grant, 1982; Ortega - Calvo et al., 1995; Tomaselli et al., 2000; Barberousse, 2006).

The influence of $w / c$ ratio on the accelerated fouling was negligible. The reason is related to experimental conditions rather than to modest difference in porosity between two studied mortars. Indeed, the relative humidity in the laboratory test chamber is permanently very high (i.e. from 80 to $100 \%$ ) (Fig. 8). In this condition, the water content into the samples is always abundant and so is sufficient to the algal development. 


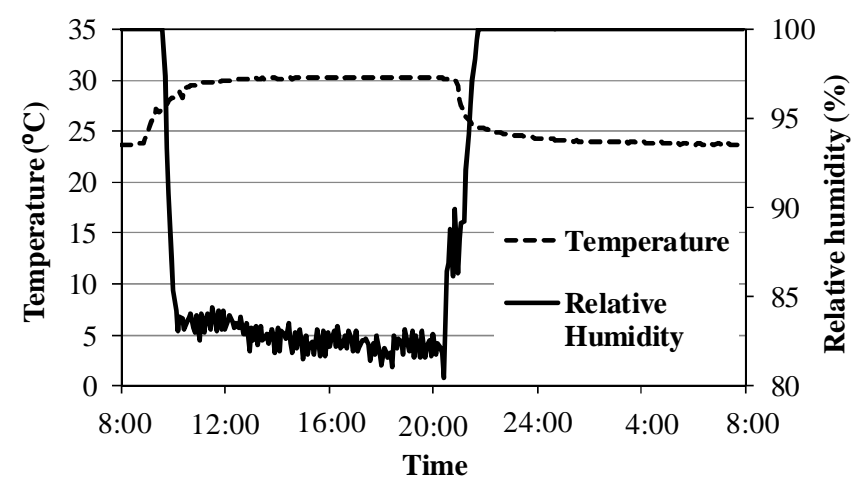

Fig. 8. Daily cycle of temperature and relative humidity in the test chamber.

$$
q \%)=100 \times \frac{V_{\text {water }}}{V_{\text {sample }}}=100 \times \frac{m_{\text {water }}}{\rho_{\text {water }} \times V_{\text {sample }}}
$$

$V_{\text {water }}$ : volume of water absorbed by the sample $\left(\mathrm{cm}^{3}\right)$;

$V_{\text {sample: }}$ apparent volume of the sample $\left(\mathrm{cm}^{3}\right)$, calculated from three dimensions of sample; the mass of sample in the humid condition and in the dry one.

$$
\rho_{\text {water }}: \text { density of water }\left(1 \mathrm{~g} . \mathrm{cm}^{-3}\right)
$$

The humid sample weight was measured 6 times along the diurnal cycle and 2 times along the nocturnal one. Before the start of accelerated fouling test, the sample was dried at $40{ }^{\circ} \mathrm{C}$ until obtaining constant weight. This weight was considered as the mass of dry sample. sprinkling cycle and remained constant during all the nocturnal period. During the diurnal period, the water evaporated under the warming effect induced by neon lights. However, the 
amount of evaporated water was weak. Indeed, at the end of the diurnal period, the remaining water into the mortars filled at least $75 \%$ and $60 \%$ of the porosity of uncarbonated and carbonated samples, respectively.

The water, being an indispensable element for the biological metabolism, is thus no longer a limiting factor for the biological development. This observation was confirmed by previous studies regarding two mortars made with $w / c$ ratios equal to 0.5 and 1 (Tran et al., 2012; 2013). Despite of the considerable difference in porosity, these mortars exhibited completely identical bioreceptivity.

In natural condition, the impact of the $w / c$ ratio on the colonization rate of samples was exhibited. The microbial fouling seemed to be favored by the highest $w / c$ ratio (1.2).

To evaluate the porous network of mortars, analyses were performed after 17 months of exposure to the outdoor conditions. PIM's results indicate a modification of the porous network. Indeed, the total porosity of the 1C-R3 and 1.2C-R3 mortars increased from 32 to 36 $\%$ and from 36 to $38 \%$, respectively. Moreover, the single peak characterizing the pore entrance diameter shifted to larger diameters (Fig. 9). Indeed, the pore inlet diameter, that was equal to $0.3 \mu \mathrm{m}$ at the beginning of outdoor exposure, was about $0.5 \mu \mathrm{m}$ at the end of the experiment for the $1 \mathrm{C}$ mortar. For the $1.2 \mathrm{C}$ mortar, the pore inlet diameter evolved from 0.75 to $1.6 \mu \mathrm{m}$. The enlargement of the pore entrance diameter could be due to the leaching effect by rain and to the activities of biological agent such as bacterial communities and/or fungi (Warscheid and Braams 2000). These results, which corresponded to the average values of the entire thickness of samples, might be amplified at the surface. 


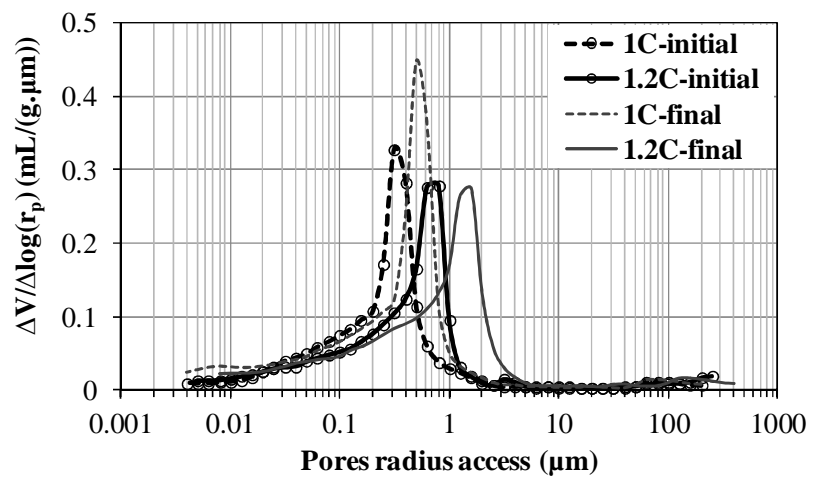

Fig. 9. Pore size distribution of carbonated mortars with a $w / c$ ratio of 1 and 1.2 at the beginning and end of the in-situ test.

The mortars made with a $w / c$ ratio of 1.2 were more porous than those formulated with a $w / c$ ratio of 1 and exhibited a greater bioreceptivity. The effect of porosity on the biofouling rate of samples exposed outdoor are in agreement with the literature (Warscheid et al., 1993; Ohshima et al., 1999; Crispim et al., 2003; Prieto and Silva, 2005; Miller et al., 2006; Miller et al., 2009).

Previous studies highlighted an important role of roughness on the biological colonization (Prieto and Silva, 2005; Miller et al., 2006; Miller et al., 2009; Tran et al., 2012; Tran et al., 2013). By providing asperities, the roughness favors the physical attachment of microorganisms which is dispersed by the water flow or the wind. Consequently, the rougher the surface is, earlier the biological fouling begins and faster the colonization is. The recent accelerated fouling experiments allow confirming the effect of roughness. Indeed, the three grades of roughness studied induced a discriminating effect on the colonization rate. The same results were noticed by Tran et al. (2012) on others mortars mixed with a $w / c$ ratio of 0.5 .

For in-situ samples, the visible biofouling due to phototrophic organisms appeared approximately at the same moment whatever the roughness of mortars. Indeed, for all the roughnesses, the first spots were detected after about 13 and 15 months of exposure. Based on 
the results of laboratory tests, the in-situ samples of the roughness R3 should have been firstly colonized, successively followed by mortars of the roughness R2 and then R1. However, in the in-situ test, the season, the external relative humidity and temperature could impact the colonization and thus hided the roughness effect.

In the natural conditions, only two grades of roughness were observed. The two roughest mortars showed the same bioreceptivity to pigmented organisms despite considerably different roughness. This tendency remains coherent with that obtained in laboratory test. In fact, a nonlinear relationship between roughness and algal fouling rate is noticed. A close bioreceptivity was observed between mortars of high roughness (Tran et al., 2012). The nondifferentiation in the outdoor test could be induced by a natural inoculation much less intense than in accelerated tests.

\section{Concerning the accelerated carbonation, this intrinsic characteristic of the samples} appeared as the most important parameter which affected the biological growth in the accelerated fouling test. Unlike the effect of roughness which favors the ability of algae to physically cling to the surface, the $\mathrm{pH}$ and/or carbonation disturbs the biological metabolism. Carbonation leads to a decrease in the surface $\mathrm{pH}$ of samples and to a lower increase in $\mathrm{pH}$ of the algal suspension flowing on test specimens. Consequently, the $K$. flaccidum algal cells are in less alkaline conditions and thus in less stressful environment for their growth with carbonated samples than with uncarbonated ones. Indeed, $K$. flaccidum is known as an acidophilic microorganism. The ability of attaching and growth of algae on a surface are thus promoted by the carbonated of samples (Tran et al., 2012; 2013).

The growth of the algal spots on the sample surface is the consequence of the vegetative and cellular multiplication which is favored at low pH (Škaloud, 2006). The attachment of algae on the surface of the substrate is governed by adaptive metabolic interactions between 
algal cells and the substrate (Fattom and Shilo, 1984; Finlay et al., 2002; Barberousse et al., 2006). The algal extracellular polysaccharides could play the role of glue (Robins et al., 1986; Gantar et al., 1995; Barberousse et al., 2006). These metabolites depend on the algal species considered and the substrate. They are involved in the initial contact between the cell and the surface, and act over time (Barberousse et al., 2006).

As a consequence, carbonated mortars are highly receptive to colonization by microorganisms. Algal colonization begins much earlier, and occurs faster compared to the uncarbonated mortars.

In the field-scale test, the influence of carbonation was not highlighted. Indeed, the biofouling of mortars, carbonated or uncarbonated, was detected at the same moment. Perhaps, the favorable climatic conditions and sufficient inoculation conditions were not met at the beginning of testing. In fact, the samples were exposed through the summer. Therefore, spring, the most favorable season for the microorganism spreading and their growth was past. Hence, the microbial colonization of carbonated samples was not initiated despite a favorable surface $\mathrm{pH}$. After one year of exposure, the mortars were aged and weathered by leaching and natural carbonation. Consequently, the same surface $\mathrm{pH}(\mathrm{pH}=8)$ was measured for all the samples whatever their initial carbonation state. The bioreceptivity of mortars is thus identical when favorable conditions to the biological development have been in place. Therefore, the influence of the initial surface $\mathrm{pH}$ on biofouling is completely inhibited.

\section{Conclusion}

The present research has investigated the effect of the intrinsic parameters (porosity, roughness and carbonation) of mortars on their biofouling by photosynthetic organisms. This study was conducted by both laboratory accelerated tests and in-situ ones. 
The impact of porosity on the biofouling of mortars is different for the two experimental test scales. This parameter has no effect on the biofouling rate in laboratory tests due to the experimental conditions. However, although more experiments of verification still required for the field-scale tests, high porosity seems to favor the biological colonization.

For the both test scales, the influence of the roughness is evidenced. A rough surface enhances the biological attachment. The discrimination of roughness grades was better in the accelerated tests than in the field-scale ones. This result could be explained by the fact that the accelerated test is performed in a closed circuit with an intense inoculation while the in-situ test involves natural inoculation.

Thanks to its experimental configuration, the laboratory tests allow revealing the role of the accelerated carbonation. It is considered as a decisive parameter in the accelerated fouling. Indeed, carbonated mortars lead to a lower $\mathrm{pH}$ value of the mortar surface and the algal suspension in the test chamber. The algal development is thus significantly promoted and so the colonization rate is remarkably accelerated in the case of carbonated mortars. While in the natural conditions, due to numerous uncontrolled and random environmental factors, the effect of the carbonation was not observed. The evolution of biofouling is identical on the both carbonated and uncarbonated mortars. Due to the long exposure time and progressive ageing by lixiviation and carbonation, the surface $\mathrm{pH}$, and thus the alkalinity, of carbonated and uncarbonated samples is the same.

The divergence of results between the laboratory and field-scale tests, prevent to correlate the two experimental scales. These dissimilarities could be remediated by improving the experimental protocol. In the accelerated test, a drying phase of samples between two sprinkling cycles could allow highlighting the role of porosity. A reasonable choice of the beginning of sample exposure to natural environment could highlight the effect of 
528 carbonation. The effect of roughness in accelerated test could be closer than that in natural

529 test by decreasing the inoculation intensity. This decrease in inoculation process could be 530 achieved by reducing, either the initial concentration of the algal suspension or either the run531 off. 


\section{References}

534

535

536

537

538

539

540

541

542

543

544

545

546

547

548

549

550

551

552

553

554

555

Ariño, X., \& Saiz-Jimenez, C., 1996. Factors affecting the colonization and distribution of cyanobacteria, algae and lichens in ancient mortars. In 8th International Congress on Deterioration and Conservation of Stone, Berlin, 725-731.

Barberousse, H., 2006. Etude de la diversité des algues et des cyanobactéries colonisant les revêtements de façade en France et recherche des facteurs favorisant leur implantation, PhD thesis, Muséum National d'Histoire Naturelle, Paris, France.

Barberousse, H., Ruiz, G., Gloaguen, V., Lombardo, R.J., Djediat, C., Mascarell, G. et al., 2006. Capsular polysaccharides secreted by building façade colonisers: characterisation and adsorption to surfaces. Biofouling 22(6), 361-370.

Crispim, C.A., Gaylarde, P.M., Gaylarde, C.C., 2003. Algal and cyanobacterial biofilms on calcareous historic buildings. Current Microbiology 46, 79-82.

CSTB, 2005. Salissures de façade : comment les éviter ? Exemples de solutions techniques. Guide pratique du CSTB.

Darlington, A., 1981. Ecology of walls. Heineman, London.

De Muynck, W., Ramirez, A.M., Belie, N.D., Verstraete, W., 2009. Evaluation of strategies to prevent algal fouling on white architectural and cellular concrete. International Biodeterioration and Biodegradation 63, 679-689.

Deruelle, S., 1991. Rôle du support dans la croissance des microorganismes. Matériaux et Construction 24, 163-168.

Dubosc, A., 2000. Etude du développement de salissures biologiques sur les parements en béton: Mise au point d'essais accélérés de vieillissement, $\mathrm{PhD}$ thesis, Institut National des Sciences Appliquées, Toulouse, France. 
Dubosc, A., Escadeillas, G., Blanc, P.J., 2001. Characterization of biological stains on external concrete walls and influence of concrete as underlying material. Cement and Concrete Research 31, 1613-1617.

Fattom, A., Shilo, M., 1984. Hydrophobicity as an adhesion mechanism of benthic cyanobacteria. Applied and Environmental Microbiology 47, 135-143.

Finlay, J.A., Callow, M.E., Ista, L.K., Lopez, G.P., Callow, J.A., 2002. The influence of surface wettability on the adhesion strength of settled spores of the green alga Enteromorpha and the diatom Amphora. Integrative and Comparative Biology 42, 11161122.

Gadelmawla, E.S., Koura, M.M., Maksoud, T.M.A., Elewa, I.M., Soliman, H.H., 2002. Roughness parameters. Journal of Materials Processing Technology 123, 133-145.

Gantar, M., Rowell, P., Kerby, N.W., 1995. Role of extra- cellular polysaccharides in the colonization of wheat (Triticum vulgarie L.) roots by $\mathrm{N}_{2}$-fixing cyanobacteria. Biology and Fertility of Soils 19, 41-48.

Gaylarde, C.C., Gaylarde, P.M., 2005. A comparative study of the major microbial biomass of biofilms on exteriors of buildings in Europe and Latin America. International Biodeterioration and Biodegradation 55, 131-139.

Grant, C., 1982. Fouling of terrestrial substrates by algae and implications for control - a review. International Biodeterioration Bulletin 18, 57-65.

Grant, C., Bravery, A.F., 1985. A new method for assessing the resistance of stone to algal disfigurement and the efficacy of chemical inhibitors. Proceedings of the Vth international congress on deterioration and conservation of stone, Presses polytechniques romandes, Lausanne, pp. 663-674.

Guillitte, O., 1995. Bioreceptivity: A new conception for building ecology studies. Science of the Total Environment 167, 215-220. 
Guillitte, O., Dreesen, R., 1995. Laboratory chamber studies and petrographical analysis as bioreceptivity assessment tools of building materials. Science of the Total Environment $167,365-374$.

Houst, Y.F., 1992. Diffusion de gaz carbonatation et retrait de la pâte de ciment durcie, PhD thesis, Ecole Polytechnique Fédérale de Lausanne, Switzerland.

Joshi, C.D., Mukunda, U., 1997. Algal disfigurement and degradation of architectural paints in India. Paintindia 47, 27-32.

Lafhaj, Z., Goueygou, M., Djerbi, A., \& Kaczmarek, M., 2006. Correlation between porosity, permeability and ultrasonic parameters of mortar with variable water/cement ratio and water content. Cement and Concrete Research 36, 625-633.

Lengsfeld, K., Krus, M., 2004. Microorganisms on facades - reasons, consequences and measures. In: IEA - Annex 41 “Moist-Eng” meeting. Glasgow, UK.

Loh, W.S., 2002. Product development for green productivity - a case study / Development of algae resistant surface coating for building facades in the humid tropics. Proceedings of the $2^{\text {nd }}$ World Conference on Green Productivity, Manila, Philippines.

Maury-Ramirez, A., De Muynck, W., Stevens, R., Demeestere, K., De Belie, N., 2013. Titanium dioxide based strategies to prevent algal fouling on cementitious materials. Cement and Concrete Composites 36, 93-100.

Miller, A., Dionísio, A., Macedo, M.F., 2006. Primary bioreceptivity: A comparative study of different Portuguese lithotypes. International Biodeterioration and Biodegradation 57, 136142.

Miller, A.Z., Dionísio, A., Laiz, L., Macedo, M.F., Saiz-Jimenez, C., 2009. The influence of inherent properties of building limestones on their bioreceptivity to phototrophic microorganisms. Annals of Microbiology 59, 705-713. 
Monge, J., 2007. Fissuration des mortiers en couches minces - Effets de l'hydratation, du séchage et de la carbonatation, PhD thesis, Ecole Normale Supérieure de Cachan, Paris, France.

Ortega-Calvo, J.J., Ariño, X., Hernandez-Marine, M., Saiz-Jimenez, C., 1995. Factors affecting the weathering and colonization of monuments by phototrophic microorganisms. Science of the Total Environment 167, 329-341.

Ohshima, A., Matsui, I., Yuasa, N., Henmi, Y., 1999. A study on growth of fungus and algae on mortar. Transactions of the Japan Concrete Institute 21, 173-178.

Perrichet, A., 1984. Développement de micro-organismes à la surface des bétons et enduits. Matériaux et Construction 17(2), 173-177.

Pietrini, A.M., Ricci, M., Bartolini, M., Giuliani, M.R., 1985. A reddish colour alteration caused by algae on stoneworks. Proceedings of the Vth international congress on deterioration and conservation of stone, Presses polytechniques romandes, Lausanne, 653662.

Prieto, B., Silva, B., 2005. Estimation of the potential bioreceptivity of granitic rocks from their intrinsic properties. International Biodeterioration and Biodegradaton 56, 206-215.

Škaloud, P., 2006. Variation and taxonomic significance of some morphological features in european strains of Klebsormidium (Klebsormidiophyceae, Streptophyta). Nova Hedwigia $83,533-550$.

Robins, R.J., Hall, D.O., Shi, D.J., Turner, R.J., Rhodes, M.J.C., 1986. Mucilage acts to adhere cyanobacteria and cultured plant cells to biological and inert surfaces. FEMS Microbiology Letters 34, 155-160.

Thiery, M., 2005. Modélisation de la carbonatation atmosphérique des matériaux cimentaires; prise en compte des effets cinétiques et des modifications microstructuraleset hydriques, PhD thesis, Ecole Nationale des Ponts et Chaussées de Paris, France. 
Tomaselli, L., Lamenti, G., Bosco, M., Tiano, P., 2000. Biodiversity of photosynthetic microorganisms dwelling on stone monuments. International Biodeterioration and Biodegradation 46, 251-258.

Tran, T.H., Govin, A., Guyonnet, R., Grosseau, P., Lors, C., Garcia-Diaz, E., Damidot, D., Deves, O., Ruot, B., 2012. Influence of the intrinsic characteristics of mortars on biofouling by Klebsormidium flaccidum. International Biodeterioration and Biodegradation 70, 31-39.

Tran, T.H., Govin, A., Guyonnet, R., Grosseau, P., Lors, C., Damidot, D., Deves, O., Ruot, B., 2013. Avrami's law based kinetic modeling of colonization of mortar surface by algae Klebsormidium flaccidum. International Biodeterioration and Biodegradation 79, 73-80.

Warscheid, Th., Braams, J., 2000. Biodeterioration of stone: a review. International Biodeterioration and Biodegradation 46, 343-368.

Warscheid, Th., Becker, T., Braams, J., Bruggerhoff, S., Gehrmann, C., Krumbein, W.E. \& Petersen, K., 1993. Studies on the temporal development of microbial infection of different types of sedimentary rocks and its effect on the alterioration of the physico-chemical properties in building materials. In Consevation of stone and other materials, M. Thiel (Ed.), E \& FN Spon, London, 303-310.

Wee, Y.C., Lee K.B., 1980. Proliferation of algae on surfaces of buildings in Singapore. International Biodeterioration Bulletin 16, 113-117.

Young, M.E., 1997. Biological growth and their relationship to the physical and chemical characteristics of sandstones before and after cleaning, $\mathrm{PhD}$ thesis, The Robert Gordon University, Aberdeen, Scotland. 